\title{
Wear Properties of TiN Coating on AISI M2
}

Martín Ortiz-Domínguez ${ }^{1}$, Oscar Gómez-Vargas², Jose Solis-Romero², Irving Morgado-González ${ }^{3}$, Alberto Arenas-Flores ${ }^{3}$ and Jorge Zuno-Silva ${ }^{1}$

${ }^{1}$ Universidad Autónoma del Estado de Hidalgo, Ciudad Sahagún, Hidalgo, Mexico, ${ }^{2}$ Instituto Tecnológico de Tlalnepantla, Estado de México, México, Distrito Federal, Mexico, ${ }^{3}$ Universidad Autónoma del Estado de Hidalgo, Mineral de la Reforma, Hidalgo, Mexico

Application of hard coatings to improve the resistance of tooling to withstand adhesive and abrasive wear underwent a significant development program within the past decades. Surface hardening treatments used in the metal-mechanic industry generally fall into two categories, diffusion (carburizing, nitriding, boriding, and carbo-boro-nitriding) and overlay coating (TiN) [1-6]. A hard layer on a soft surface can reduce friction and wear by preventing fissuring at both the macro and the micro-level. Such a layer typically has residual compressive stress, which can prevent the occurrence of tensile forces. A further reduction of friction and wear can be achieved by increasing the stiffness of the carrying load by increasing the hardness of the substrate, which inhibits the deflection and fissuring resulting from the load of the countersurface. In this regard, Physical Vapor Deposition (PVD) coatings present advanced properties such as high hardness, high melting point, low friction coefficient, high wear resistance, chemical stability, and corrosion resistance. Uses of these coatings can be found in the metal-working industry, biomedical applications, micro-electronics industry and for decorative purposes [7-11]. The current work aimed to analyze the microstructure of the TiN coating on AISI M2 high-speed steel produced by powder metallurgy is seen as a possibility of a reduction in the rate of crack propagation. Finally, the pin-on-disc tests were employed to carry out a comparative study between the TiN + AISI M2 and substrate in terms of wear behavior. The specimen sizes are following MPIF STANDARD 41, the tested samples had a disc shape with a diameter of $25.4 \mathrm{~mm}$ and a thickness of $10 \mathrm{~mm}$. The chemical composition of the material is: $0.80 \% \mathrm{C}, 4.13 \% \mathrm{Cr}, 1.00 \% \mathrm{Co}, 0.30 \% \mathrm{Mn}, 5.00 \% \mathrm{Mo}, 0.45 \% \mathrm{Si}, 1.90 \% \mathrm{~V}$, and $6.50 \% \mathrm{~W}$ (weight $\%$ ). Figure 1 shows the cross-sections by SEM for the AISI M2. The three samples were cleaned using sputtering etching with $650 \mathrm{~V}, 240 \mathrm{kHz}, 1600 \mathrm{~ns}$ for $15 \mathrm{~min}$. The TiN coatings (see Figure 2) were obtained by using a target with high power impulse magnetron sputtering (HIPIMS) with $2000 \mathrm{~W}, 500 \mathrm{~Hz}, 200 \mathrm{~ns}$ and three targets with direct current magnetron sputtering (DCMS) with $2500 \mathrm{~W}$ on each (see Figure 3). The sputtering targets were $\mathrm{Ti}(>99.8 \%$ ). Interlayers of pure Ti were deposited with $400 \mathrm{~V}$ bias-voltage on all substrates. TiN coatings were deposited by using bias-voltages of $75 \mathrm{~V}$ and $150 \mathrm{~V}$. The TiN coatings had thicknesses of approximately $1 \mu \mathrm{m}$ and $2 \mu \mathrm{m}$. The coatings were deposited at $450^{\circ} \mathrm{C}$ with a Nitrogen/Argon (99.97\% pure) atmosphere (Ar: $\mathrm{N}_{2}$ Ratio $\left.=24: 5\right)$ and total pressure of $350 \mathrm{mPa}$ and 120 min of exposure time. The hard samples were ground with $\mathrm{SiC}$ abrasive paper up to grit 2500. Afterward, the samples were polished using a diamond suspension with a particle size of $6 \mu \mathrm{m}$, finishing with a particle size of $3 \mu \mathrm{m}$. The depth of the surface coatings and morphology were analyzed by SEM and EDS (JEOL JSM-6360 LV at $20 \mathrm{kV}$ ). The pin-on-disc tests were performed in dry sliding conditions at ambient temperature by means of a CSM tribometer, with a relative humidity of 40 pct. Before the tests, the samples were cleaned with acetone to remove the contaminants from the surface. All tests were then made for a total sliding distance of $100 \mathrm{~m}$ with a sliding speed of $0.08 \mathrm{~m} / \mathrm{s}$, and the covered radial distance was $14 \mathrm{~mm}$ under a normal load of $5 \mathrm{~N}$. The CSM tribometer was used to determine the magnitude of the friction coefficient and wear as two surfaces rub together. Figure 4 shows the cross-section and the EDS analysis obtained by SEM at the TiN/substrate interphase for the AISI M2 steel. This result demonstrates that the formed the TiN top coating produced a hardness in the expected range, around $2500 \mathrm{HV}$, and no 
incompatibility with the supporting substrate was observed. The pin-on-disc wear test was performed on the substrate and TiN coating through the examination of change in the friction coefficient vs sliding distance in dry conditions. Figure 5 describes the change in the friction coefficient as a function of the sliding distance when applying a diamond indenter over the surfaces of tested materials. The evolution of the tangential force according to the sliding distance allowed us to distinguish three different phases from the obtained curves. During the first phase, the friction coefficient of the substrate and TiN coating are low from 0 to $20 \mathrm{~m}$ of sliding distance. The friction coefficient of the TiN coating is nearly constant $(\mu=$ 0.197), and the friction coefficient of the substrate increases progressively. This phase can be considered as an incubation period. It corresponds to the indenter slip on the samples (substrate and TiN coating), in the absence of all major damage. The diff erence between the two friction coefficients in this first phase is due to the diff erence that exists in the surface roughnesses during this first phase. A second phase exists where the friction coefficient of the substrate increases progressively, until a maximal value of 0.523 is reached, while the friction coefficient of the TiN coating decreases until a value of 0.212 . This phase is associated with the apparition of wear particles on the diamond indenter trails. A third phase occurs where the friction coefficient of the substrate stabilizes between 0.525 and 0.513 , whereas for the TiN coating, it stabilizes from 0.2122 to 0.2127 . It seems that this phase is associated with an abrasive action by the wear particles previously formed. Therefore, the stabilization of the friction coefficient values of the substrate and TiN coating is probably due to the grinding of the removed particles. It is noted that the substrate has a friction coefficient value higher than that of the TiN coating. Finally, the key advantages of these technologies compared to diffusion coatings are that no distortion of substrate material and no phase transformation are apparent.

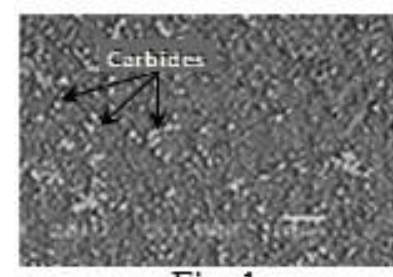

Fig. 1

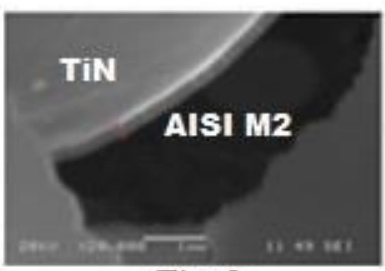

Fig. 2

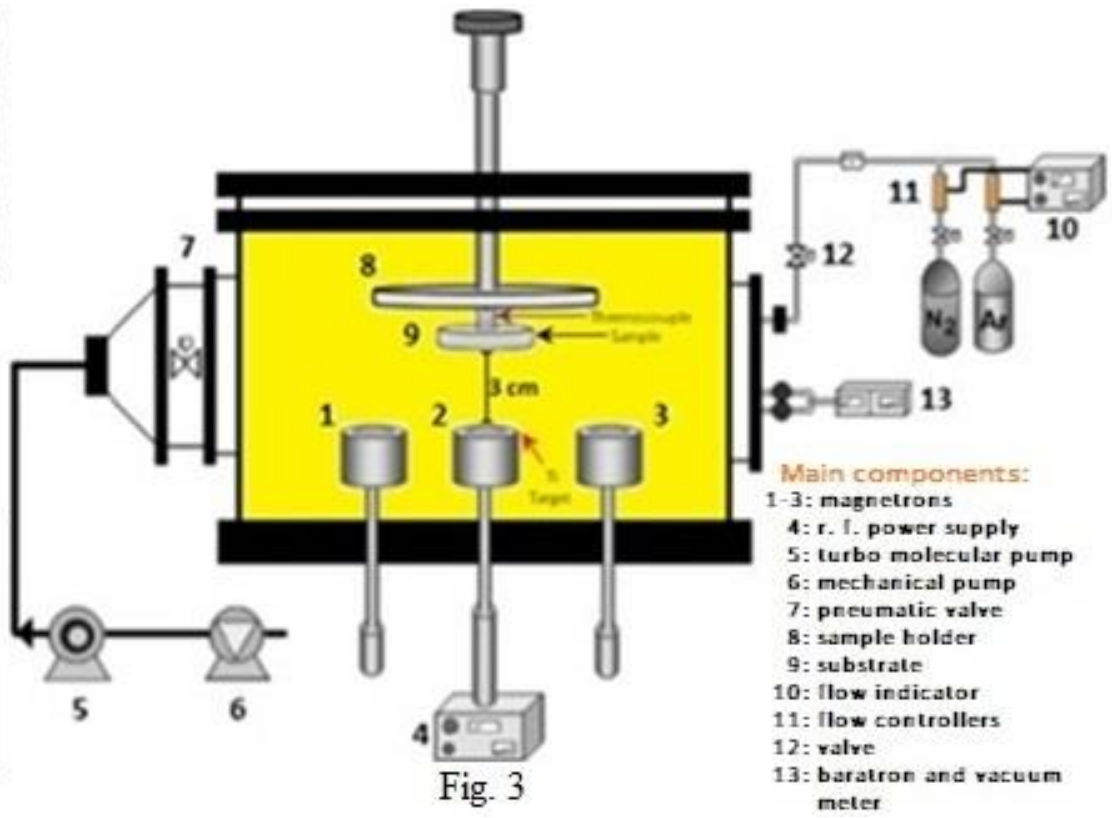

Figure 1. (Figure 1) SEM cross-sectional micrograph of AISI M2 steel, SEM (Figure 2) cross-sectional micrograph at the surface of the TiN coating developed on the surface of AISI M2 steel, and the schematic representation of the deposition reactor (Figure 3). 


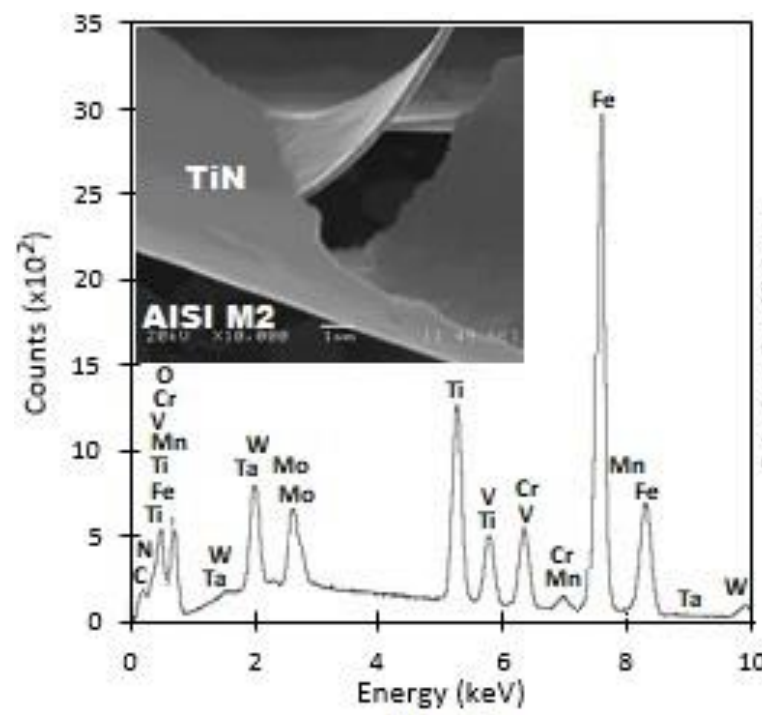

Fig. 4

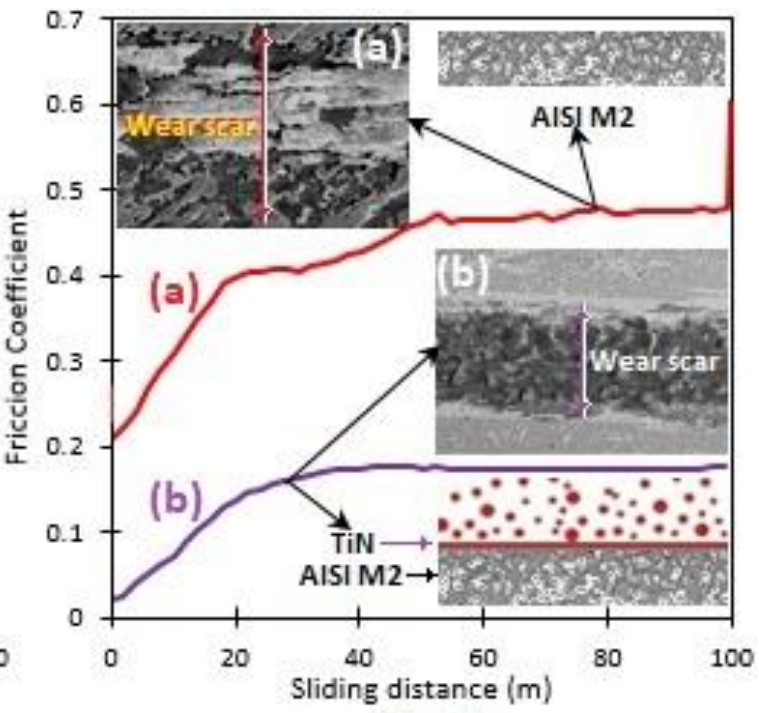

Fig. 5

Figure 2. (Figure 4) SEM cross-sectional micrograph and EDS analysis of AISI M2 steel and SEM (Figure 5) cross-sectional micrographs of the wear scar on surfaces of AISI M2 steel: (a) substrate surface and (b) TiN coating surface. Likewise, the variation of the friction coefficient of the diamond indenter during sliding against the substrate surface (see Figure 5(a)) and TiN coating surface (see Figure 5(b)).

References

[1] J. R. Davis. "Surface Hardening of Steels: Understanding the Basics”, 1st ed. ASM, Ohio, p. 213.

[2] M. Ortiz-Domínguez, I. Morgado-González, A. Cruz-Avilés, A. Soto-García, R. Trujillo-Sánchez, M. L. Moreno-González, G. Moreno-González, O. A. Gómez-Vagas, J. Zuno-Silva, Microsc.Microanal. 25 (Suppl 2) 2019, p. 2400.

[3] M. Ortiz-Domínguez, O. A. Gómez-Vargas, I. Simón-Marmolejo, M. A. Flores-Rentería, L. E. Martínez-Martínez, A. Cruz-Avilés, M. A. Paredes-Rueda, Microsc. Microanal. 24 (Suppl 1) 2018, p. 1076.

[4] O. A. Gómez-Vagas, M. Ortiz-Domínguez, A. Cruz-Avilés, I. Morgado-González, J. Solis-Romero, V. A. Castellanos-Escamilla, E. Coronel-Guerra, E. Cardoso-Legorreta, Microsc. Microanal. 25 (Suppl 2) 2019, p. 770.

[5] O. A. Gómez-Vargas, M. Ortiz-Domínguez, J. Solís-Romero, A. Arenas-Flores, I. Morgado González, J. Zuno-Silva, F. R. Barrientos-Hernández and J. Medina-Marín, Microsc. Microanal. 25 (Suppl 2) 2019, p. 796.

[6] M. Ortiz-Domínguez, O. A. Gómez-Vargas, G. Ares de Parga, G. Torres-Santiago, R. VelázquezMancilla, V. A. Castellanos-Escamilla, J. Mendoza-Camargo, and R. Trujillo-Sánchez, Advances in Materials Science and Egineering. 2019 (2019), p. 1.

[7] K. Y. Li and Z. D. Xiang, Surf. Coat. Technol. 204 (2010), p. 2268.

[8] H. Du and J. Agren, Z. Metallkd. 86 (1995), p. 522.

[9] K. H. Habig, Mater. Eng. 2 (1980) p. 83.

[10] M. Flores, S. Muhl, L. Huerta, Surf. Coat. Technol. 200 (2005) p.1315-1319.

[11] J. L. Bernal, E. Vera, A. I. Martínez, A. García, Microsc. Microanal. 24 (Suppl 1) 2018, p. 1102. 